\title{
Transarterial embolization of renal cell carcinoma as an adjunctive therapy prior to cryoablation: a propensity score matching analysis
}

\author{
Andrew J. Gunn (1) \\ Benjamin J. Mullenbach (1) \\ May M. Poundstone (i) \\ Jennifer B. Gordetsky (D) \\ Edgar S. Underwood $\mathbb{C}$ \\ Soroush Rais-Bahrami 무
}

From the Division of Interventional Radiology (A.J.G. $₫$ agunn@uabmc.edu, B.J.M., M.M.P, E.S.U.), Department of Radiology, and Departments of Pathology (J.B.G.), and Urology (S.R.), University of Alabama at Birmingham, Birmingham, AL, USA.

Received 1 March 2018; revision requested 28 March 2018; last revision received 1 May 2018; accepted 9 May 2018.

Published online 23 October 2018.

\begin{abstract}
PURPOSE
We aimed to assess the safety and effectiveness of transarterial embolization (TAE) prior to percutaneous cryoablation (PCA) in the management of renal cell carcinoma (RCC) compared with PCA alone using a propensity score matching analysis to minimize confounding factors.
\end{abstract}

\section{METHODS}

A retrospective review of all PCAs performed for renal masses identified 9 patients who underwent TAE prior to PCA. These patients were matched in a 2:1 ratio with patients who underwent PCA only using age, gender, and tumor size to create the propensity score model for matching. Other demographic, clinical, and outcomes data were collected.

\section{RESULTS}

The TAE+PCA group included 5 males and 4 females with a mean age of 67.9 years and mean tumor diameter of $51.7 \mathrm{~mm}$. The PCA only group included 11 males and 7 females with a mean age of 66.8 years and mean tumor diameter of $46.2 \mathrm{~mm}$. No significant differences in these propensity score matched characteristics were identified. Further, the groups had no significant differences in tumor geometry $(P=0.831)$, R.E.N.A.L. nephrometry scores $(P=0.144)$, or comorbidity indices $(P=0.392)$. TAE was technically successful and without complication in all cases. PCA was technically successful in 8 of 9 patients in the TAE+PCA group and in 14 of 18 patients in the PCA only group $(P=0.483)$. No significant differences in the rate of complications $(P=0.483)$, change in eGFR $(P=0.691)$, or change in hematocrit $(P=0.152)$ were identified between the two groups.

\section{CONCLUSION}

TAE of RCC prior to PCA is safe and technically feasible; however, no objective benefits over PCA alone were identified by propensity score matching analysis. Due to small sample size and limitations of the study, no definite conclusions should be drawn. Larger, prospective studies of this therapeutic approach are warranted.
T here will be an estimated 64000 new cases of renal cell carcinoma (RCC) diagnosed in 2017, accounting for approximately $4 \%$ of all new cancer diagnoses in the United States (1). Classically, some patients will present with flank pain, gross hematuria, or a palpable flank mass, while others may present late with symptoms secondary to local tumor progression or distant metastases (2). Yet, an increasing number of patients are being diagnosed with asymptomatic, incidentally found RCC due to both increased utilization of cross-sectional imaging and improved imaging techniques (3-7). These incidentally discovered RCCs are typically smaller, of lower grade, and are associated with longer patient survival than symptomatic masses (8). Traditionally, standard therapeutic options for patients with RCC included either radical or partial nephrectomy (2). However, given the increasing number of smaller RCCs, minimally invasive and nephron-sparing approaches such as laparoscopic ablation and percutaneous ablation have been successfully employed as alternatives to surgery (8-14). Percutaneous ablation is an attractive treatment option for patients who are not optimal surgical candidates or who may wish to avoid traditional surgery that has similar outcomes to partial nephrectomy in T1a RCC (15).

Although RCC includes a variety of histologic subtypes, the most common subtype, clear cell RCC, is characterized as a hypervascular tumor on contrast-enhanced imaging (16). 
The vascularity of RCC tumors may provide practitioners with an opportunity to deliver adjunctive therapies either prior to or in combination with percutaneous ablation via a transarterial route. For example, transarterial embolization (TAE) prior to percutaneous ablation has already been shown to improve oncologic outcomes in hepatocellular carcinoma (HCC), which is another highly vascular tumor (17). Apart from potential oncologic benefits, it has been theorized that TAE of RCC prior to percutaneous ablation may also reduce the risk of bleeding (18). Furthermore, if TAE is undertaken with ethiodized oil as the contrast agent, tumor localization and lesion coverage during computed tomography (CT)-guided percutaneous ablation may also be enhanced (19). Indeed, prior investigations have found that the combination of TAE followed by percutaneous ablation is safe and technically feasible (18-25). Nevertheless, prior reports are limited by their descriptive design (case reports and case series). Therefore, the purpose of this study is to compare the technical and clinical outcomes of patients whose renal masses were treated with combined TAE and percutaneous cryoablation (PCA) to those treated with PCA alone using a propensity score matching analysis.

\section{Methods}

Patients, data collection, and propensity score matching model

This study was approved by our Institutional Review Board and was compliant with the Health Insurance Portability and Accountability Act. Given its retrospective nature, informed consent from patients was not required. A review of our radiology information system identified nine patients who underwent combined TAE plus PCA for a renal mass between January 1, 2008 and December 31, 2016 as well as 167 additional patients who underwent PCA alone as therapy for their renal masses during the

\footnotetext{
Main points

- Transarterial embolization (TAE) prior to percutaneous cryoablation for renal cell carcinoma (RCC) is technically feasible.

- TAE prior to percutaneous cryoablation for RCC did not result in any adverse outcomes or increased complications.

- TAE prior to percutaneous cryoablation for RCC did not provide improved technical success or clinical outcomes.
}

same time period. Cryoablation is the most commonly used modality for treating RCC at our institution. Only PCA patients were included in this study to limit heterogeneity that may be introduced by including patients treated with thermal ablation. $\mathrm{Pa}$ tient data and tumor characteristics, including age, race, sex, number of renal masses, and tumor diameter were collected. A propensity score model was created using a multivariate logistic regression based on age, sex, and greatest tumor diameter. This method controlled for imbalances in potentially confounding factors among the discrete study cohorts we evaluated. Individuals in the PCA-only cohort were then matched in a 2:1 ratio based upon propensity scores which combined continuous and categorical factors to the reference cohort
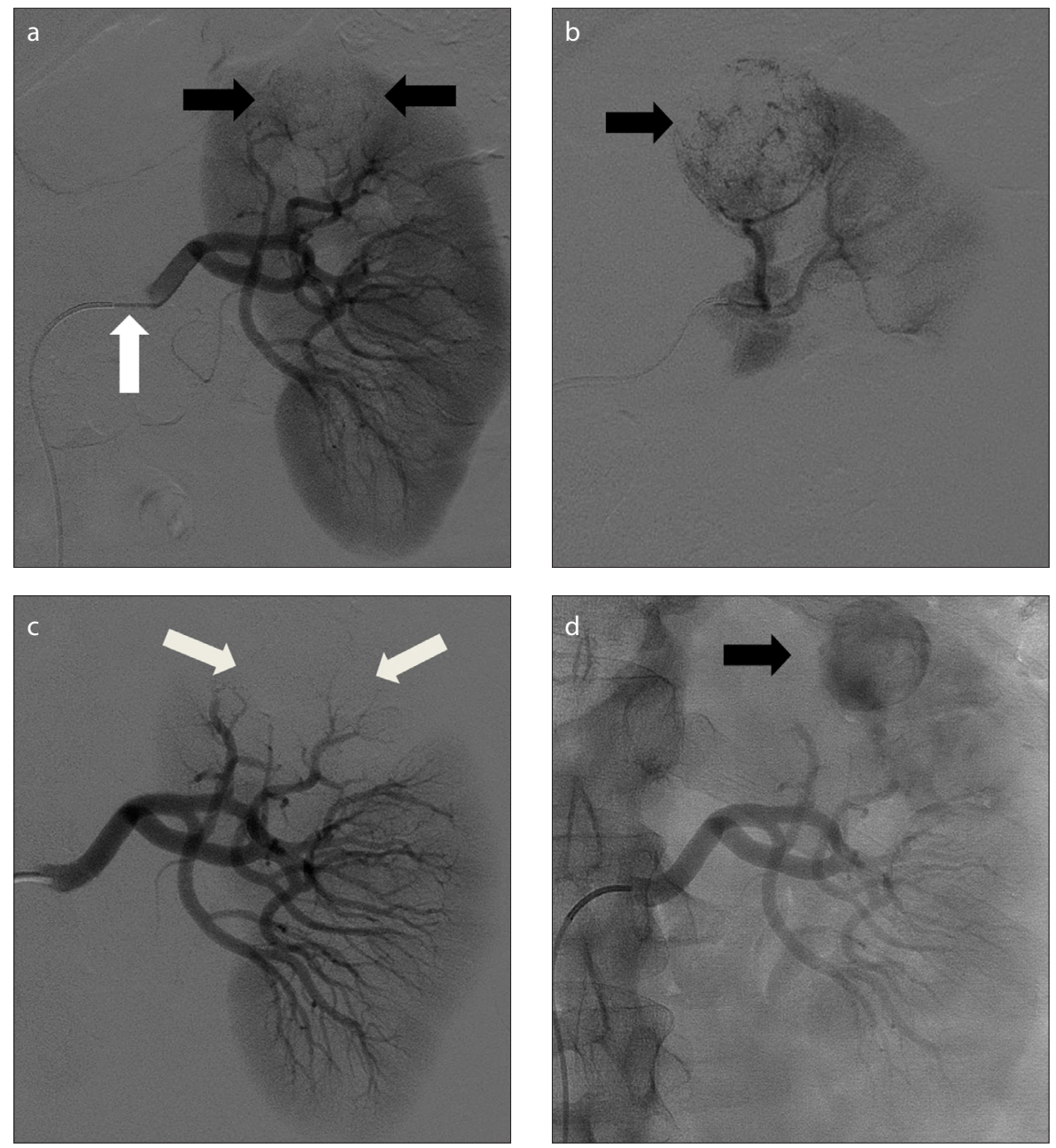

Figure 1. a-d. A 55-year-old male with a $2.8 \mathrm{~cm}$ mass in the upper pole of the left kidney. Digital subtraction angiography (DSA) image (a) with the diagnostic catheter in the left renal artery (white arrow) identifies subtle vascular irregularity in the upper pole (black arrows). DSA image (b) with the microcatheter in the renal arterial branch feeding the tumor (black arrow). Postembolization DSA image (c) demonstrates no residual vascularity in the tumor (white arrows). Embolization was performed with ethanol mixed with contrast followed by particles mixed with contrast. Unsubtracted postembolization DSA image (d) demonstrates the embolized mass in the upper pole (black arrow). 

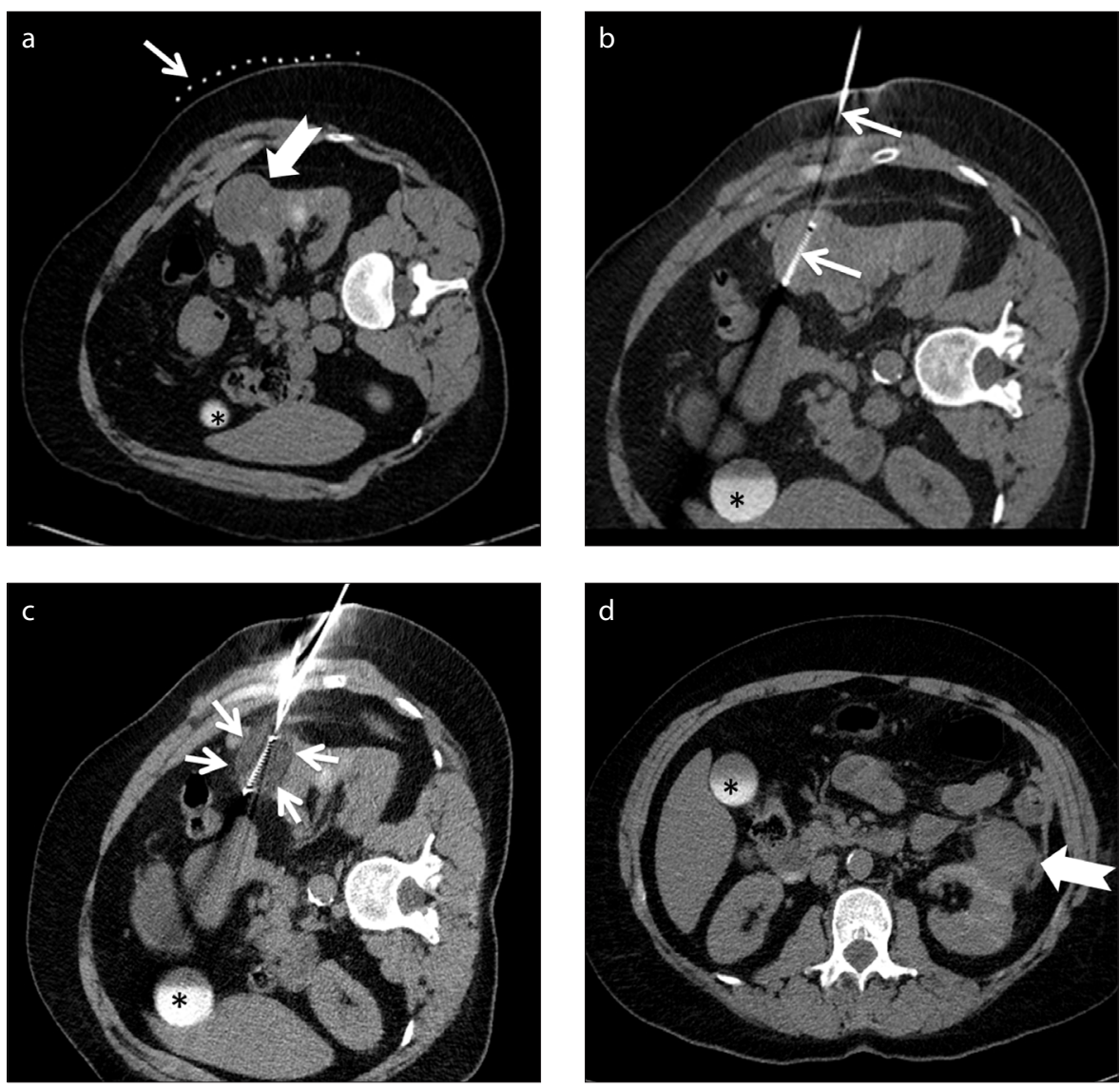

Figure 2. a-d. A 52-year-old female with a $5.1 \mathrm{~cm}$ mass in the left kidney. Limited CT image (a) with the patient in right lateral decubitus position prior to cryoablation shows the exophytic mass on the left kidney (thick white arrow). A localizing grid is seen on the patient's skin (thin white arrow). The patient was given intravenous contrast to better localize the tumor margins which explains the subtle hyperattenuation in the renal parenchyma and vicarious excretion of contrast in the gallbladder (asterisk in all panels). Limited CT image (b) in right lateral decubitus positions shows one of the three cryoablation probes (thin arrows) in position prior to ablation. Limited CT image (c) with the patient in right lateral decubitus position shows the hypodense iceball forming during ablation (thin arrows), which allows for monitoring of the ablation zone. Postablation CT image (d) with the patient in supine image demonstrates expected postablation changes (thick white arrow).

Transarterial embolization of the renal mass

A board-certified interventional radiology physician performed all TAE. Blood thinning-medications were appropriately held (28). The vascular access site (the right common femoral artery in all cases) was prepared and draped in standard sterile fashion. Vascular access was obtained under sonographic guidance using a micropuncture set (Angiodynamics), as is standard at our institution. A $6 \mathrm{~F}$ vascular sheath (Terumo) was then placed over a 0.035 -inch wire that comes with the set to secure arterial access. After accessing the appropriate renal artery with a $5 \mathrm{~F}$ diagnostic catheter (Cobra 2 or Sos $\mathrm{Omni}^{\oplus} 2$, Angiodynamics) angiography was performed to identify the tumor and its supplying vessels (Fig. 1). The artery or arteries supplying the tumor were selected using a microcatheter and microwire combination (2.8F Progreat $^{\oplus}$, Terumo). Once appropriate positioning had been confirmed, embolization was performed under fluoroscopy to prevent reflux into nontarget vessels. Technical success for TAE was defined as the embolization of all feeding arteries to stasis without further tumoral blush on postembolization angiography. Complications were classified according to criteria from the Society of Interventional Radiology (SIR) (29).

\section{Percutaneous cryoablation of the renal mass}

A board-certified interventional radiology physician performed all PCA using Galil ${ }^{\mathrm{TM}}$ cryoablation probes (BTG). Routine prophylactic antibiotics were administered (30) and blood-thinning medications were appropriately held (28). Preliminary CT scan was obtained in order to localize the mass. Once a safe percutaneous route was identified, the site was prepared and draped in standard sterile fashion. The probe(s) were then advanced into position under CT guidance and ablation performed per the instructions for use (Fig. 2). Hydrodissection was required in one patient in the PCA only group. Technical success for PCA was defined as complete coverage of the renal mass during the ablation session or sessions, if a staged ablation was planned. Complications were classified according to criteria from the SIR (29). Measures of oncologic outcomes such as need for repeat ablation, recurrence, and patient survival were also recorded.

\section{Statistical analysis}

Patient and procedural parameters were compared across the two propensity score matched patient cohorts (TAE+PCA vs. PCA only). Categorical statistics were compared using chi-square probability testing with Fischer exact modification when warranted by frequency observed. For continuous variables, a normal distribution is expected in the patient population from which these cases were derived and are thus reported as mean \pm standard deviation (SD). Continuous variables were compared using Student's t-test. A predetermined $P$ value of 0.05 was considered the threshold for statistical significance.

\section{Results}

Patient characteristics are summarized in Table 1. Patients were well-matched using the propensity score analysis according to age $(P=0.831)$, sex $(P=0.783)$, and maximum tumor diameter $(P=0.264)$. Furthermore, no statistically significant differences were identified between the two groups according race $(P=0.322)$, tumor geometry $(P=0.831)$, Charlson comorbidity index $(P=0.392)$, or R.E.N.A.L. nephrometry score ( $P=0.144)$ despite not being purposefully matched for these parameters. All patients in both groups had a single renal mass. All patients in both groups had a platelet count above $50 \times 10^{3} / \mu \mathrm{L}$ and an international normalized ratio (INR) of $<1.5$ at the time of their procedures. Reasons for patient referral for percutaneous ablation are summarized in Table 2. Biopsy, when performed, was done at the time of ablation. Pathology was available for 8 of 9 patients (89\%) in the $\mathrm{TAE}+\mathrm{PCA}$ group and demonstrated clear 
Table 1. Patient characteristics

\begin{tabular}{|c|c|c|c|}
\hline Characteristic & $\mathrm{TAE}+\mathrm{PCA}$ & PCA only & $P$ \\
\hline Age (years) & $67.9 \pm 12.5$ & $66.8 \pm 11.4$ & 0.831 \\
\hline $\operatorname{Sex}(M / F), n(\%)$ & $5(56) / 4(44)$ & $11(61) / 7(39)$ & 0.783 \\
\hline Tumor diameter (mm) & $51.7 \pm 17.9$ & $46.2 \pm 7.0$ & 0.264 \\
\hline Tumor geometry, n (\%) & & & 0.831 \\
\hline Exophytic & $4(44)$ & $6(33)$ & \\
\hline Endophytic & $2(22)$ & $4(22)$ & \\
\hline Mixed & $3(33)$ & $8(44)$ & \\
\hline R.E.N.A.L. nephrometry score, n (\%) & & & 0.144 \\
\hline$\leq 6$ & $2(22)$ & $7(39)$ & \\
\hline 7-9 & $6(67)$ & $5(28)$ & \\
\hline$\geq 9$ & $1(11)$ & $6(33)$ & \\
\hline CCl score, n (\%) & & & 0.392 \\
\hline $1-3$ & $3(33)$ & $4(22)$ & \\
\hline $4-6$ & $4(44)$ & $12(67)$ & \\
\hline$\geq 7$ & $2(22)$ & $2(11)$ & \\
\hline
\end{tabular}

\begin{tabular}{ll}
\hline Table 2. Indications for referral for percutaneous ablation & n \\
\hline TAE+PCA group & 3 \\
\hline Presence of a second malignancy & 3 \\
\hline Cardiac comorbidities* & 2 \\
\hline History of prior surgery that would increase operative risk & 2 \\
\hline Chronic obstructive pulmonary disease & 2 \\
\hline Chronic kidney disease & 1 \\
\hline Obesity & 1 \\
\hline Advanced age & 2 \\
\hline PCA only group & 9 \\
\hline Chronic kidney disease & 6 \\
\hline Cardiac comorbidities* & 4 \\
\hline Obesity & 3 \\
\hline Patient preference & 3 \\
\hline Presence of a second malignancy & 3 \\
\hline Cirrhosis & 3 \\
\hline History of prior surgery that would increase operative risk & 2 \\
\hline Chronic obstructive pulmonary disease & 2 \\
\hline Advanced age & 3 \\
\hline Includes: coronary artery disease, congestive heart failure, history of mitral valve repair, and atrial fibrillation.
\end{tabular}

cell RCC ( $n=5)$, oncocytoma vs. oncocytic chromophobe hybrid RCC $(n=1)$, necrotic tissue $(n=1)$, and normal renal parenchyma not felt to represent the lesion in question $(n=1)$. Pathology was available for 10 of 18 patients (56\%) in the PCA only group and demonstrated clear cell RCC $(n=6)$, papillary RCC $(n=3)$, and normal renal parenchyma not felt to represent the lesion in question $(n=1)$. No instances of the embolic material interfering with the pathologic analysis were recorded.

All TAE was done as an outpatient procedure except for one patient who was already hospitalized due to ongoing symptomatic hematuria. Conscious sedation was provided using a combination of fentanyl and midazolam in eight patients, while general anesthesia was used in one patient at that patient's request. The choice of embolic material was operator-dependent but included particles mixed with contrast $(n=4)$, particles mixed with ethiodized oil $(n=2)$, particles mixed with contrast followed by microcoils $(n=1)$, ethanol mixed with contrast followed by particles mixed with contrast $(n=1)$, and microcoils alone $(n=1)$. The ratios of mixed embolic agents (i.e., particles mixed with ethiodized oil) were not available in the medical record. However, particle size ranged from 250-900 $\mu \mathrm{m}$. TAE was technically successful in all patients. No major or minor complications were encountered.

PCA was performed at a mean of $10.8 \pm 6.4$ days (range, 1-20 days) in the nine patients in the TAE+PCA group. After ablation, six patients were admitted for overnight monitoring, two patients were discharged the same day, and one patient had the procedure as an in-patient for symptomatic hematuria from the renal mass. In the PCA alone group, nine patients were admitted for overnight observation and nine patients were discharged home the same day. Per review of the notes, the decision to observe patients overnight was made due to either the size of the lesion ablated, patient preference, or treating physician preference. Conscious sedation using a combination of fentanyl and midazolam was used in eight patients (89\%) in the TAE+PCA group with one patient requesting general anesthesia. Conscious sedation was used in 17 of 18 patients in the PCA group (94\%), with one patient receiving general anesthesia due to treating physician preference. A mean of $3.0 \pm 1.3$ probes were used to ablate the lesions in the TAE+PCA group compared 
with $3.2 \pm 1.1$ probes in the PCA alone group $(P=0.733)$. Ablations were technically successful in 8 of 9 (89\%) and 14 of 18 (78\%) patients in the TAE+PCA and PCA alone groups, respectively $(P=0.483)$. In the TAE+PCA group, the unsuccessful ablation was due to a rim of tissue left purposefully outside the ablation zone given its proximity to the renal pelvis. Similarly, three of the technically unsuccessful ablations in the PCA alone group were due to a portion of the tumor approximating critical structures. The fourth technically unsuccessful ablation was due to bleeding encountered during the ablation. No major complications occurred in either group. Three Minor A complications (all perinephric hematomas) were observed in the TAE+PCA group. Six Minor A complications (five perinephric hematomas, one asymptomatic pneumothorax after an intentional transpleural approach) and two Minor B complications (postprocedural hypertension requiring medication and perinephric bleeding requiring thrombin injection via a percutaneous needle) occurred in the PCA alone group. The patient requiring thrombin injection was the same patient who had an unsuccessful ablation due to bleeding. This tumor was $5.3 \mathrm{~cm}$ in size and centrally-located with a R.E.N.A.L. nephrometry score of 11 . No difference in the complication rate between the two groups was found ( $P=0.483$ ).

Since one potential benefit of TAE prior to PCA is decreased bleeding, we compared preprocedural hematocrit $(\mathrm{HCT})$ to postprocedural HCT as a surrogate for bleeding. There was a $2.1 \% \pm 15.4 \%$ decrease in HCT after the combined therapeutic approach of TAE+PCA. In the PCA alone group, there was a $9.3 \% \pm 8.3 \%$ decrease in HCT. However, the difference in percent change in HCT between the two did not reach statistical significance $(P=0.152)$. Given that one potential drawback of a combined TAE+PCA approach is the extra iodinated contrast material delivered to the kidney, we compared the patients' pre- and postprocedural estimated glomerular filtration rates (eGFR). In the TAE+PCA group, there was a $2.8 \% \pm 20.9 \%$ decrease in eGFR after the combined therapy. There was a $1 \% \pm 23.2 \%$ increase in eGFR after therapy in the PCA alone group. No significant difference was found in the change in eGFR between the two groups $(P=0.691)$.

The mean clinical follow-up was 30.8 months (range, 7-59 months) and 22.1 months (range, 3-98 months) in the TAE+ PCA and PCA alone groups, respectively. Four patients that received combined therapy required a second ablation session for residual disease on initial surveillance imaging performed at 3 months. All of these patients had renal masses greater than $5 \mathrm{~cm}$ in size (range, $5.1-8.4 \mathrm{~cm}$ ). None underwent a second TAE session prior to their second PCA. Five patients in the PCA alone group required additional cryoablation sessions for residual disease (mean tumor diameter, $4.9 \mathrm{~cm}$; range, 4.0-6.2 cm) on initial surveillance imaging. In the follow-up period, one patient in the TAE+PCA group with a $2.8 \mathrm{~cm}$ mass was found to have recurrent tumor at approximately 13 months postablation and was re-treated with PCA alone. One patient in the PCA alone group with a $4.4 \mathrm{~cm}$ mass was also found to have recurrent tumor at approximately 35 months postablation and was re-treated with PCA alone. Otherwise, the remainder of patients in both groups had no recurrent or residual disease during the follow-up period. Mean survival calculations and a Kaplan-Meier analysis were not performed because 6 of 9 patients are still living in the TAE+PCA group while the same is true for 10 of 18 patients in the PCA alone group.

\section{Discussion}

RCC is a hypervascular tumor that may benefit from TAE prior to percutaneous ablation, similar to HCC and other hypervascular tumors, in order to improve oncologic outcomes, decrease bleeding, and enhance tumor localization during ablation (31). Hall et al. (18) were the first to describe TAE prior to percutaneous ablation for RCC in the radiology literature. Their case report described the treatment of a 67-year-old female with an incidentally found $3.0 \mathrm{~cm} \mathrm{RCC}$. The mass was noted to bleed significantly during biopsy so the decision was made to embolize the lesion with $300 \mu \mathrm{m}$ polyvinyl alcohol (PVA) particles prior to radiofrequency ablation (RFA). The authors were technically successful and the patient had no evidence of residual or recurrent disease at the 3-month follow-up examination. Yamakado et al. (21) published one of the earliest case series examining the safety and efficacy of TAE prior to RFA for RCCs larger than $3.5 \mathrm{~cm}$. The authors treated 12 RCCs in 11 patients with sizes ranging from 3.5 to $9 \mathrm{~cm}$. Embolization was performed with either ethanol mixed with ethiodized oil or PVA particles
(200 $\mu \mathrm{m})$ followed by percutaneous RFA. All tumors showed a significant reduction in size and remained controlled during the 13 month follow-up period. One patient developed a delayed abscess that was treated with percutaneous drainage. Arima et al. (22) published the largest case series of TAE followed by RFA to date in 2007. In this report, 28 RCCs were embolized with either ethanol mixed with ethiodized oil or PVA particles (size not specified) six days prior to percutaneous RFA. The mean diameter of tumors was $3.1 \pm 1.2 \mathrm{~cm}$ (range, 1.2-6.5 $\mathrm{cm})$. The authors reported that all tumors were adequately treated after two RFA sessions and the recurrence rate was only $2.8 \%$ during a mean follow-up period of approximately two years, but all recurrences occurred in tumors larger than $4 \mathrm{~cm}$. No major complications were encountered although five minor complications occurred (pyonephrosis, $n=1$; perinephric hematoma, $n=2$; retroperitoneal bleeding, $n=1$; postprocedural nausea, $n=1$ ). Michimoto et al. (19) described TAE prior to PCA in 17 patients with small (12-36 mm), endophytic RCCs. In this report, the authors performed TAE between one and five days prior to CT-guided PCA with a mixture of ethanol and ethiodized oil in order to improve tumor localization. TAE was technically successful in 16 of 17 patients (unable to identify the tumor on angiography in one patient). PCA was technically successful in all patients with local control of RCC in $93 \%$ of patients at a mean follow-up of 15.4 months. The authors noted a statistically significant drop in patients' eGFR after the combined therapeutic approach.

The use of a propensity score matching model for patient age, sex, and tumor diameter in order to create a comparison group for standard PCA alone therapy is an advancement upon the existing literature (18-25). Our groups were also similar in several other important clinical parameters such as Charlson comorbidity index, R.E.N.A.L. nephrometry score, and tumor geometry. Our data suggest that TAE+PCA is safe as no added patient complications or ill effects on patient eGFR were seen. Ideally, however, an objective benefit should be identified with a combined approach that justifies the costs and risks associated with the extra procedure. The clinical outcomes of both groups of patients compare well with existing literature, especially given the large size of the treated lesions (18-25). Yet, 

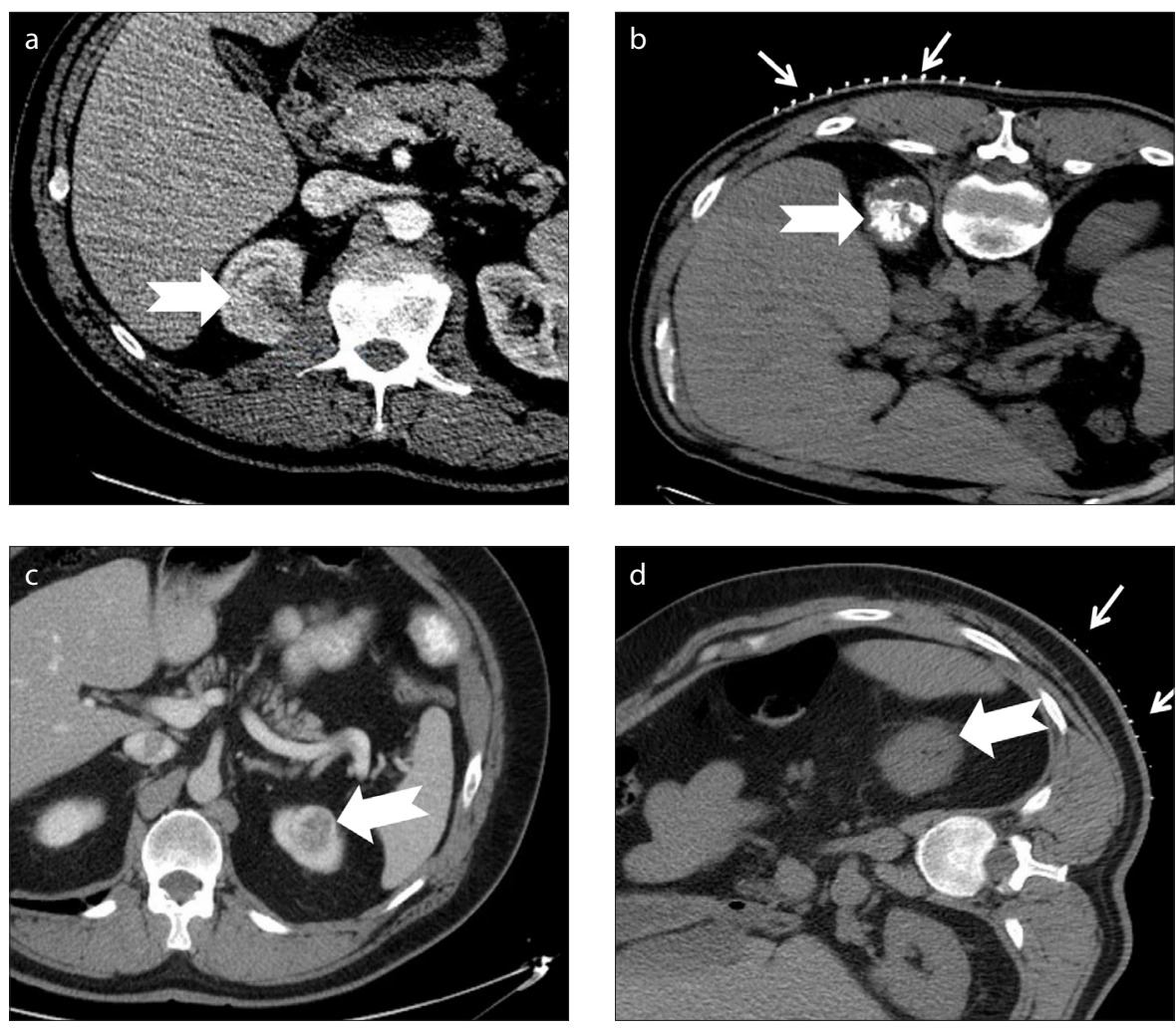

Figure 3. a-d. A 58-year-old male with a right upper pole renal mass (a, b). Axial slice (a) from a contrast-enhanced CT in portal-venous phase shows a $3.9 \mathrm{~cm}$ mass in the upper pole of the right kidney (thick white arrow). Prior to cryoablation, the mass was embolized with particles mixed with ethiodized oil. Limited CT image (b) in the same patient as in panel (a) in prone position prior to cryoablation shows the mass demarcated by the ethiodized oil (thick white arrow). A localizing grid is seen on the patient's skin (thin white arrows). A 55 year-old male with a $2.8 \mathrm{~cm}$ mass in the upper pole of the left kidney (c, d). Axial slice (c) from a contrast-enhanced CT in portal-venous phase shows a $2.8 \mathrm{~cm}$ mass in the upper pole of the left kidney (thick white arrow). Prior to cryoablation, this mass was embolized with ethanol mixed with contrast followed by particles mixed with contrast. Limited CT image (d) in the same patient as in panel (c) in right lateral decubitus position prior to cryoablation. The mass (thick white arrow) is much more difficult to differentiate from normal renal parenchyma without the ethiodized oil. A localizing grid is seen on the patient's skin (thin white arrows).

we were unable to demonstrate an objective advantage of this combined approach in improving the technical success of PCA or in reducing its complications. For example, one of the most common complications of PCA is bleeding, which can occur in $3.5 \%-14 \%$ of patients $(32,33)$. Theoretically, performing a TAE prior to PCA should lessen the risk of serious bleeding events. There was a smaller absolute drop in HCT after TAE+PCA compared to PCA alone, though not statistically significant. This result was likely skewed by a single patient who had a $27 \%$ increase in HCT after TAE+PCA. Upon review, this patient was the same patient described previously who underwent both TAE and PCA as an in-patient for preexisting, symptomatic hematuria. Already anemic prior to undergoing any therapy for RCC (HCT, 26\%), the patient was transfused prior to her next lab draw despite not hav- ing any complication or blood loss during her procedures resulting in a postprocedural HCT of $33 \%$.

Identifying the RCC prior to percutaneous ablation may not pose a problem for larger, exophytic tumors but can be difficult when there are multiple masses in the same kidney, endophytic tumors, or smaller lesions. Operators may depend on anatomic landmarks or give intravenous contrast to localize the RCC during CT-guided percutaneous ablation procedures. Nonetheless, one subjective benefit of TAE prior to percutaneous ablation may be enhanced tumor localization when ethiodized oil is the contrast agent employed (19). Ethiodized oil is also an embolic agent; however, it is most commonly used to make other embolic agents visible during fluoroscopy. After the TAE, it is retained within the RCC, allowing for better appreciation of the mass during PCA (Fig. 3). Improved tumor localization can help to assure the treating physician that the entire tumor is being included within the ablation zone. This could potentially reduce the number of re-treatments due to residual tumor. Additionally, complete tumor coverage during the initial ablation session has important oncologic benefits as well given that incomplete ablation may have stimulatory effects on tumor progression secondary to alterations in the tumor microenvironment (34). However, these subjective observations would need to be verified with further investigations and larger patient series powered to evaluate these endpoints.

There are several limitations to this study. First, its retrospective design did not allow us to control for important variables such as the embolic agent or mixture of embolic agents, timing of laboratory assessments, time between TAE and PCA, and follow-up imaging intervals. Second, even though our report is similar in size to previously published case series, it is hindered by small sample size despite the 2:1 matching algorithm employed. Third, despite using propensity score matching, the tumors in the TAE+PCA group tended to be larger than the PCA alone tumors which was seen based on the weighted average given to the tumor diameter characteristic in the propensity score assignments being most significant over age and sex. This fact is important to note given that larger tumors are more difficult to ablate and are associated with higher recurrence rates (4). The matching overcame this limitation as much as possible given the TAE+PCA patient data available. Importantly, this difference did not reach statistical significance. This is representative of a clear operator bias where the larger and more difficult to ablate lesions were selected for the combined therapeutic approach. This limitation could be rectified if evaluated in a prospective manner. Fourth, we do not have pathology results on all the lesions treated. Even though all lesions were suspicious of RCC secondary to their growth or imaging appearance, pathologic confirmation on all masses would add strength to our findings. Finally, given that the majority of patients were still living, we were unable to make a comparison about overall or disease-specific mortality between the two groups. Given these limitations, the small sample size, and nonstatistically significant results, no defi- 
nite conclusions should be drawn. Yet, the current report adds to the body of literature on this subject by attempting to control for confounding variables.

In conclusion, future directions in research should include data collection in a prospective, randomized fashion or a meta-analysis of existing retrospective studies. Other directions could include a focus on newer embolic agents (i.e., liquid embolics, radiopaque particles) and different ablative technologies (i.e., microwave ablation, irreversible electroporation). Prior reports have demonstrated that dynamic, contrast-enhanced $C T$ and $C T$ perfusion may be able to help predict the vascularity of $\operatorname{RCC}(35,36)$. Thus, there remains an open question of whether it is possible to objectively identify patients who may benefit more than others from TAE prior to PCA. Further, there may be value in objectively assessing the success of TAE by measuring embolic uptake within the lesion by intraprocedural cone-beam CT or preablation CT if ethiodized oil or radiopaque particles are used.

\section{Conflict of interest disclosure \\ The authors declared no conflicts of interest.}

\section{References}

1. Siegel RL, Miller KD, Jemal A. Cancer statistics, 2017. CA Cancer J Clin 2017; 67:7-30. [CrossRef]

2. Rini BI, Campbell SC, Escudier B. Renal cell carcinoma. Lancet 2009; 373:1119-1132. [CrossRef]

3. Pantuck A J, Zisman A, Belldegrun AS. The changing natural history of renal cell carcinoma J Urol 2001; 166:1611-1623. [CrossRef]

4. Gervais DA, McGovern F J, Arellano RS, McDougal WS, Mueller PR. Radiofrequency ablation of renal cell carcinoma: part 1, indications, results, and role in patient management over a 6-year period and ablation of 100 tumors. AJR Am J Roentgenol 2005; 185:64-71. [CrossRef]

5. Zagoria RJ, Hawkins AD, Clark PE, et al. Percutaneous CT-guided radiofrequency ablation of renal neoplasms: factors influencing success. AJR Am J Roentgenol 2004; 183:201-207. [CrossRef]

6. Jayson M, Sanders $H$. Increased incidence of serendipitously discovered renal cell carcinoma. Urology 1998; 51:203-205. [CrossRef]

7. Rais-Bahrami S, Guzzo TJ, Jarrett TW, Kavoussi LR, Allaf ME. Incidentally discovered renal masses: oncologic and perioperative outcomes in patients with delayed surgical intervention. BJU Int 2009; 103:1355-1358. [CrossRef]

8. Levinson AW, Su L-M, Agarwal D, et al. Longterm oncological and overall outcomes of percutaneous radio frequency ablation in high risk surgical patients with a solitary small renal mass. J Urol 2008; 180:499-504. [CrossRef]

9. Huang WC, Elkin EB, Levey AS, Jang TL, Russo P. Partial nephrectomy versus radical nephrectomy in patients with small renal tumors-is there a difference in mortality and cardiovascular outcomes? J Urol 2009; 181:55-61. [CrossRef]
10. Miller DC, Schonlau M, Litwin MS, Lai J, Saigal CS; Urologic Diseases in America Project. Rena and cardiovascular morbidity after partial or radical nephrectomy. Cancer 2008; 3:511-520. [CrossRef]

11. Bandi G, Hedican SP, Nakada SY. Current practice patterns in the use of ablation technology for the management of small renal masses at academic centers in the United States. Urology 2008; 71:113-117. [CrossRef]

12. Hinshaw JL, Shadid AM, Nakada SY, Hedican SP, Winter TC III, Lee FT Jr. Comparison of percutaneous and laparoscopic cryoablation for the treatment of solid renal masses. AJR Am J Roentgenol 2008; 191:1159-1168. [CrossRef]

13. Zlotta AR, Wildschutz T, Raviv G, et al. Radiofrequency interstitial tumor ablation (RITA) is a possible new modality for treatment of renal cancer: ex vivo and in vivo experience. J Endourol 1997; 11:251-258. [CrossRef]

14. Psutka SP, Feldman AS, McDougal WS, McGovern FJ, Mueller P, Gervais DA. Long-term oncologic outcomes after radiofrequency ablation for T1 renal cell carcinoma. Eur Urol 2013; 63:486-492. [CrossRef]

15. Liu N, Huang D, Cheng $X$, et al. Percutaneous radiofrequency ablation for renal cell carcinoma vs. partial nephrectomy: comparison of long-term oncologic outcomes in both clear cell and non-clear cell of the most common subtype. Urol Oncol 2017; 35:530.e1-530.e6. [CrossRef]

16. Lin SP, Bierhals AJ, Lewis JS Jr. Best cases from the AFIP: metastatic renal cell carcinoma. Radiographics 2007; 27:1801-1807. [CrossRef]

17. Takaki H, Yamakado K, Nakatsuka A, et al. Radiofrequency ablation combined with chemoembolization for the treatment of hepatocellular carcinomas $5 \mathrm{~cm}$ or smaller: risk factors for local tumor progression. J Vasc Interv Radiol 2007; 18:856-861. [CrossRef]

18. Hall WH, McGahan JP, Link DP, deVere White RW. Combined embolization and percutaneous ablation of a solid renal tumor. AJR Am J Roentgenol 2000; 174:1592-1596. [CrossRef]

19. Michimoto K, Shimizu K, Kameoka Y, Sadaoka S, Miki J, Kishimoto K. Transcatheter arterial embolization with a mixture of absolute ethanol and iodized oil for poorly visualized endophytic renal masses prior to CT-guided percutaneous cryoablation. Cardiovasc Intervent Radiol 2016; 39:1589-1594. [CrossRef]

20. Tacke J, Mahnken A, Bucker A, Rohde D, Gunther RW. Nephron-sparing percutaneous ablation of a $5 \mathrm{~cm}$ renal cell carcinoma by superselective embolization and percutaneous RF-ablation. Rofo 2001; 173:980-983. [CrossRef]

21. Yamakado K, Nakatsuka A, Kobayashi S, et al. Radiofrequency ablation combined with renal arterial embolization for the treatment of unresectable renal cell carcinoma larger than 3.5 $\mathrm{cm}$ : initial experience. Cardiovasc Intervent Radiol 2006; 29:389-394. [CrossRef]

22. Arima K, Yamakado K, Kinbara H, Nakatsuka A Takeda K, Sugimura Y. Percutaneous radiofrequency ablation with transarterial embolization is useful for treatment of stage 1 renal cell carcinoma with surgical risk: results at 2-year mean follow up. Int J Urol 2007; 14:585-590. [CrossRef]
23. Gebauer B, Werk M, Lopez-Hanninen E, Felix $\mathrm{R}$, Althaus P. Radiofrequency ablation in combination with embolization in metachronous recurrent renal cancer in solitary kidney after contralateral tumor nephrectomy. Cardiovasc Intervent Radiol 2007; 30:644-649. [CrossRef]

24. Mondshine RT, Owen S, Mondschein Jl, Cizman B, Stavropoulos SW, Clark TW. Combination embolization and radiofrequency ablation therapy for renal cell carcinoma in the setting of coexisting arterial disease. J Vasc Interv Radiol 2008; 19:616-620. [CrossRef]

25. Nakasone $Y$, Kawanaka K, Ikeda O, Tamura Y, Yamashita Y. Sequential combination treatment (arterial embolization and percutaneous radiofrequency ablation) of inoperable renal cell carcinoma: single-center pilot study. Acta Radiol 2012; 53:410-414. [CrossRef]

26. Gervais DA, McGovern FJ, Arellano RS, McDougal WS, Mueller PR. Renal cell carcinoma: clinical experience and technical success with radio-frequency ablation of 42 tumors. Radiology 2003; 226:417-424. [CrossRef]

27. Kutikov A, Uzzo RG. The R.E.N.A.L. nephrometry score: a comprehensive standardized system for quantitating renal tumor size, location and depth. J Urol 2009; 182:844-853. [CrossRef]

28. Patel IJ, Davidson JC, Nikolic B, et al. Consensus guidelines for periprocedural management of coagulation status and hemostasis risk in percutaneous image-guided interventions. J Vasc Interv Radiol 2012; 23:727-736. [CrossRef]

29. Omary RA, Bettmann MA, Cardella JF, et al. Quality improvement guidelines for the reporting and archiving of interventional radiology procedures. J Vasc Interv Radiol 2003; 14:S293295. [CrossRef]

30. Venkatesan AM, Kundu S, Sacks D, et al. Practice guideline for adult antibiotic prophylaxis during vascular and interventional radiology procedures. J Vasc Interv Radiol 2010; 21:16111630. [CrossRef]

31. Winokur RS, Pua BB, Madoff DC. Role of combined embolization and ablation in management of renal masses. Semin Intervent Radiol 2014; 31:82-85. [CrossRef]

32. Schmit $\mathrm{CH}$, Callstrom MR, Boorjian SA, et al. A comparison of bleeding complications in patients undergoing percutaneous renal cryoablation using cryoprobes with and without heatbased track ablation. J Vasc Interv Radiol 2018; 29:874-879. [CrossRef]

33. Kakarala B, Frangakis CE, Rodriguez R, Georgiades CS. Hemorrhagic complications of percutaneous cryoablation for renal tumors: results from a 7-year prospective study. Cardiovasc Intervent Radiol 2016; 39:1604-1610. [CrossRef]

34. Shuch B, Linehan WM. Kidney cancer: Is incomplete renal ablation linked to tumour progression? Nat Rev Urol 201; 9:547-548. [CrossRef]

35. Wang JH, Min PQ, Wang PJ, et al. Dynamic CT evaluation of tumor vascularity in renal cell carcinoma. AJR Am J Roentgenol 2006; 186:14231430. [CrossRef]

36. Reiner CS, Roessle M, Thiesler T, et al. Computed tomography perfusion imaging of renal cell carcinoma: systematic comparison with histopathological angiogenic and prognostic markers. Invest Radiol 2013; 48:183-191. [CrossRef] 